Chapter 8

\title{
Cultural Value as Practice: seeing future directions, looking back at AHRC Cultural Value Project
}

\author{
Dr Patrycja Kaszynska \\ Senior Research Fellow, Social Design Institute, University of the Arts London \\ Research Associate, Culture, King's College London \\ Research Affiliate, New College of the Humanities at Northeastern
}




\begin{abstract}
This chapter introduces the AHRC Cultural Value Project and the ensuing legacy work. It suggests that this work has resulted in the re-positioning of the field of inquiry into cultural value by shifting attention away from policy constructs and towards lived experiences; away from measuring the outcomes of cultural participation and towards understanding the process of engagement. The challenge still remaining is to develop an empirically grounded pragmatist account of cultural value as a form of practice-a situated interface of agents, actions and structures taking place in an institutionalised and materially circumscribed environment. Reconceiving cultural value in these terms will have profound methodological implications, not least the challenge of finding methodologies appropriate to its analysis within the realm of historically and geographically variable relations and structures. It is however a challenge worth taking. The proposed shift, it is suggested, will provide a way of addressing some long-standing 'problems' arising in relation to cultural value: the separation of conditions and consciousness; the overemphasis on the cognitive at the cost of the bodily; the separation between 'the best and the brightest' and the 'everyday' conceptions of culture. The proposed approach may also drive the refinement of flat(ter)-ontology methodologies which neither succumb to methodological individualism nor overemphasise methodological structuralism.
\end{abstract}

\title{
Keywords
}

Cultural value, theories of practice, cultural policy, methodological individualism, structuralism 


\section{Introduction}

In recent years, there has been a renewed interest in cultural value. In the UK, a number of initiatives-some policy oriented and some academically driven-coincided in time to interrogate the value of arts and culture (for an example of the former see Warwick Commission, 2015; for an example of the latter, see Miles \& Gibson, 2016). Pivotal in this was a major research project supported by the Arts and Humanities Research Council. The AHRC Cultural Value Project-a 3.5 years, $£ 2.5$ million initiative which supported over 70 original pieces of work-was established with the intention of improving our understanding of the value of arts and culture and the methods used to capture this value (Crossick \& Kaszynska, 2016). It was followed by the Cultural Value Scoping Project (Kaszynska, 2017) - a collaboration between the Arts and Humanities Research Council, Paul Hamlyn Foundation, and King's College London, working in partnership with Arts Council England. Set up to explore the legacy of the AHRC Cultural Value Project, the scoping project asked explicitly how an improved understanding of cultural value might benefit three distinct but overlapping constituencies: policy makers, academics, and those working in the cultural sector. On the recommendation of the scoping project's report, the funding consortium committed to the creation of a collaborative Centre for Cultural Value - the first of its kind in the UK-which opened in Leeds in October 2019.

In a nutshell, the key messages that emerged from the first AHRC project concerned the need for a theoretical orientation that recognises the centrality of individual experience and the concomitant vindication of research methodologies better suited to capture cultural value on this level, e.g. artsbased, phenomenology-grounded and hermeneutics-derived methods and techniques. Whilst joining the first Cultural Value Project in being critical of the macro-level approaches where the effects of cultural engagement are measured in the registers derived and imposed from elsewhere (e.g. economic and social policy), the scoping project's report argued that we need to interrogate more explicitly the process whereby cultural value is articulated. The scoping project's report did not suggest that individual experiences are irrelevant; it did however hint that looking at them alone will not be sufficient to appreciate how cultural value is discursively and materially constructed through knowledge, practice, institutions and material environments. Collectively, these two initiatives-the AHRC Cultural Value Project and the Cultural Value Scoping Project-have directed the 'business' of understanding cultural value onto new territories, this business remains however fundamentally incomplete. 
Building on these two initiatives, this chapter argues that future frameworks should seek to understand how arts and culture function and are used in specific social, institutional and material contexts (see for instance Latour, 2005; Bennett, 2015). More specifically, the recommendation is that the existing analytical frameworks - those paying close attention to individual experiences and using qualitative approaches on the one hand, and the socio-structuralist approaches derived from political economy and institutionalism, on the other-are supplemented with theories of practice and the unique point of view they can offer (Reckwitz, 2002; Schatzki, 2002; Shove, Pantzar, \& Watson, 2012). Whilst presenting certain challenges, introducing the practice theoretical lens into the study of cultural value carries the promise of overcoming a number of deeply entrenched conceptual, theoretical and methodological problems. In particular, it is suggested that the proposed shift will leave us better equipped to deal with the following long-standing issues arising in relation to cultural value: the separation of conditions and consciousness; the mediation between the bodily and the cognitive; the 'type' distinction between 'the best and the brightest' and the 'everyday' when it comes to culture. The proposed approach may also drive the refinement of flat(ter)ontology methodologies which neither succumb to methodological individualism nor overemphasise methodological structuralism.

\section{Looking back-descriptively-at the AHRC Cultural Value Project}

The Cultural Value Project (2012-2015) was a research initiative set up by the Arts and Humanities Research Council in the autumn of 2012 with a self-proclaimed aim of investigating the value that the arts and culture bring to individuals and to society. To this end, the Cultural Value Project supported over 70 mostly academically led separate projects spanning small-scale original research inquiries, critical reviews of literature in key areas, and workshops, conferences and symposia. The final report from the Cultural Value Project-Understanding the value of arts and culture-was launched in April 2016. The objective of the project was to advance our understanding of cultural value and to refine the methods we use to capture and evaluate this value. The choice of words was strategic: to advance understanding rather than to evidence impact; to evaluate and capture rather than to measure, thereby not presupposing that the value of culture should always expressed in numerical and quantitative registers and, more importantly, without assuming that there is just one value register and scale. ${ }^{1}$ Indeed, the project was very much premised on the need to question the inherited language, approaches and the policy discourse which were perceived as reductive and not up to the task of capturing cultural value in terms that might be recognised by cultural practitioners and the sector at large. 
The AHRC Cultural Value Project was set up because of dissatisfaction with the inherited state of the debate where the importance of arts and culture was discussed in the context of public-money allocations, most notably, the fact that many conversations appeared to have been shaped by making case for public funding and by what publicly funded organisations think government want to hear, above all about economic benefits (see for instance Belfiore, 2002). The direct target was the New Public Management (NPM): the 'modernisation' of the managerial techniques in the public sector through private sector's means such as target setting, output monitoring and performance auditing; and the demand to resort to instrumental arguments in order to justify the spending on the arts, be it in terms of economic benefits, urban regeneration or community cohesion.

The AHRC Cultural Value Project found this approach dissatisfying for a number of reasons. Firstly, there was the problem with the credibility of the result, as the claims made were poorly evidenced and the theories of change explaining how the alleged benefits were generated poorly articulated. Secondly, as mentioned, there was an issue with the terms of the debate which did not resonate with many arts practitioners and audiences. Perhaps even more cogently, adopting the language and approaches of NPM carried the risk of losing sight of something fundamental about cultural value. The point is simply that when people engage with the arts and culture, they do not perceive the value of this engagement in terms of economic impact or an improvement to local infrastructure. Their motivations, and indeed their perception of value, seemed not to be adequately captured by the existing language and approaches. Thus, the ambition of the Cultural Value Project was to tell the 'missing story' of cultural value by making the individual engagement with culture the starting point:

The starting premise of the Cultural Value Project is that we need to begin by looking at the actual experience of culture and the arts rather than the ancillary effects of this experience. It is the cultural experience itself which will give coherence to the framework as a whole. The value begins there, with something fundamental and irreducible, and all the other components in the framework might be seen, to a greater or lesser extent, to cascade from it (Crossick \& Kaszynska, 2016, p. 21).

This shift was proposed not as an attempt to champion individualism or in order to revive some old forms of connoisseurship and the art for art's sake ideologies; it was done to shake up those approaches in cultural policy which treat as primary the auxiliary and instrumental effects in economy, health, education, etc. Needless to say, the claim was not that cultural value is somehow exhausted on the individual level but rather that individual experience - understood in an ontological sense $^{2}$ - grounds the wider 'cascading' effects which are manifest on the level of social structures and in terms of the existing constructs used to express value. ${ }^{3}$ 
The privileging of people's experiences of arts and culture is reflected in the framework approach established in the Cultural Value Project where-besides the traditional areas such as urban regeneration, economy, health, education - two fundamental components of cultural value were identified: 'the reflective individual' and 'the engaged citizen: civic agency and civic engagement'. In this context, the project turned to the questions such as: the role of cultural engagement in engendering the experiences of empathy, compassion, enhanced understanding, imaginativeness, appreciation of the diversity of human cultures, civic ethos and civil disobedience (see Crossick \& Kaszynska, 2016). Perhaps not surprisingly given these conceptual readjustments, what has emerged in relation to methodological considerations is that a better balance between words and numbers was needed when it comes to capturing the effects of arts participation and cultural engagement. Hand in hand with re-validating the importance of looking at individual experiences came a greater emphasis on those research approaches which studied value from the first-person perspective, such as those used in the context of phenomenology, hermeneutics, literary studies and the humanities more broadly. Moreover, the report questioned ideas about the hierarchy of evidence, in which experimental methods and randomised controlled trials are seen as the gold standard. It argued that qualitative research (with the depth that it gives) need not be less rigorous than quantitative, experimental studies (with the breadth that they provide): the fundamental criteria must be their appropriateness to the particular subject that is being looked at, and robustness in how evidence is gathered and deployed. Rigorous case studies can be a valid and important source of evidence. ${ }^{4}$

\section{Looking back-critically-at the AHRC Cultural Value Project}

"The imperative to reposition first-hand, individual experience of arts and culture is at the heart of enquiry into cultural value" (Crossick \& Kaszynska, 2016, p. 7) attracted the most attention and caused most agitation among the commentators and critics of the Cultural Value Project (see Stern \& Seifert, 2016; Farrell, 2016). In particular, a concern was voiced that the "focus on individual experience as a counterweight to the dominance of instrumental case-making can obscure the importance of social and cultural ecology in conditioning that experience" (Stern \& Seifert, 2016, p. 279). The AHRC report does implicitly recognise that individual experiences are socially positioned and conditioned; indeed, it explicitly states that "the complex nature of the effects of cultural engagement [is] a function of the dynamic processes by which the individual, the community and the contexts affect each other" (Crossick \& Kaszynska, 2016, p. 157). What it does not do is seek to explain in detail how the micro and the macro levels of analysis relate to each other, nor does it highlight possible dangers of repositioning first-hand individual experiences to the centre of analysis. Whilst it would be unreasonable to suggest that the Cultural Value Project should have pondered in 
depth and detail the old problem of structuration (see, for instance, Berger \& Luckmann, 1991; Archer, 1982; Giddens, 1984), it could be justifiably asked whether more prominence should have been given to the contextual embedding of cultural value and the concomitant considerations of how subjective points of view are shaped by objective/intersubjective social constructs and how they shape them in turn. It also might be that the project and the resulting report should have been more outspoken about the limits of the methodological frameworks prioritising individual experience. Regarding the first consideration, some developments in cultural sociology and cognitive sciences highlight the importance of appreciating the situatedness and the contextual grounding of the individual experiences of art and culture, and thereby, the difficulty of speaking of 'general' or maybe even 'universal' individual experience. As DiMaggio (1997, p. 267) points out:

Many sociologists have come to reject the latent-variable view of culture as coherent, integrated, and ambiguous in favor of representations of culture as a "toolkit"...or "repertoire"...: a collection of stuff that is heterogeneous in content and function. Yet much empirical work on culture still presumes that culture is organized around national societies or cohesive subnational groupings, is highly thematized, and is manifested in similar ways across many domains... ${ }^{5}$

What we know from the recent developments in cognitive psychology and social cognition is that cultural experiences-rather than being simply activated and replicated in different people-are processed using mental schemata and shared cognitive structures in ways that are not always predictable and far from uniform (see Swindler, 1986). Until we have a better understanding of these complex processes, we have to accept that when we speak of cultural value as experienced by individuals in general terms, we are likely to be making generalisations based on our rational expectations and extrapolations. What these developments in cognitive sciences also underscore is the importance of thinking of culture as supra-individual and irreducibly collective, and this in turn makes using methodologies grounded in methodological individualism problematic, such as some of those championed by the Cultural Value Project report. What is meant by methodological individualism, in the sense originally intended by Weber (1922), is that social phenomena must be explained by showing how they result from individual actions, which in turn must be explained through reference to the intentional states that motivate the individual actors. Significantly, the model of individual action assumed here is rational and contextually invariant. ${ }^{6}$ This presents a problem for accounting for cultural value not just because of the stratification of culture discussed above but also because the collective-or indeed the irreducibly collective constructs such as cultural value (see Kaszynska, 2020) - do not decompose neatly the way methodological individualism would predict them to, nor do individual preferences and experiences aggregate for these irreducibly collective constructs in the way methodological individualism assumes (see Kahneman, 2011; Rushton, 1999). Nothing said here implies that "the imperative to reposition first- 
hand, individual experience of arts and culture is at the heart of enquiry into cultural value" (Crossick \& Kaszynska, 2016, p. 7) underpinning the AHRC Cultural Value Project was necessary misguided. In fact, given the motivations of the project presented here, it might have been necessary. What these considerations do show however is that in order to arrive at a better understanding of cultural value the theoretical frames and methodological perspectives focused on individual experience have to be supplemented by other approaches and, where needed, critically re-examined in light of the existing critiques of methodological individualism.

\section{Cultural Value Scoping Project: continuities and breaks}

Compared to the AHRC Cultural Value Project, the Cultural Value Scoping Project (2016-2017) was a different type of project in terms of its scope and ambition. It was essentially intended as an 'options analysis' with the task of 'scoping' whether the new research infrastructure called for in the original report (see 'Observatory for Cultural Value' in Crossick \& Kaszynska, 2016, p. 10) was needed, and if so, how it might function and what it should do. The key point from the scoping project is that in order to understand cultural value we should not focus exclusively on the 'what': the effects, impacts and the outcomes of cultural engagement (does arts participation make us healthier?, does it drive inward investment?, etc.). We should also understand the 'how': how cultural value is articulated and how the conversations around the value of arts and culture are framed. In other words, the report from the Cultural Value Scoping Project (Kaszynska, 2017) recognises that cultural value is contested and co-constructed by different constituencies: the cultural sector and policy makers being the obvious ones, with the academics and the public at large also playing a role. The argument is that in the past there has not been enough recognition that the value of arts and culture is not so much a 'fact' to be evidentially demonstrated, as it is a 'value' that emerges through these interactions. $^{7}$

In line with what the current chapter proposes, the scoping project's report argues that, unlike facts, values are relational and produced through a relationship between what is valued, the one who is doing the valuing and the context in which valuation takes place. Moreover, these dynamics and contexts change. Consequently, cultural value should be recognised as iterative and contingent. What follows from this is that, as much as evidencing the outcomes of engagement, we need to understand the processes of how cultural value is articulated and co-produced. Not surprisingly, there are some continuities between the AHRC Cultural Value Project and the Cultural Value Scoping Project. In line with the original project, the scoping project recognises the need to ditch advocacy, to broaden our 'definition' of arts participation, and to appeal to individual experiences as a way of 
challenging the habit of thinking of cultural value in terms of policy construct imported from other policy areas, be it business, innovation, skills or local communities or health (Kaszynska, 2017). However, as mentioned above, the scoping project's report goes further in problematising the 'what' and the 'how' of cultural value. Notably, it explicitly recognises cultural value to be relational, iterative and contingent. Admittedly however-and understandably given the character of the project and the aims of this scoping exercise-the scoping project's report did not think through these implications theoretically and methodologically. The next step is thus to address this gap.

\section{Turning to Theories of Practice}

In what is often considered the foundational text of Cultural Studies, Cultural studies: two paradigms, Stuart Hall sketches the backbone for the argument in favour of practice theory, although this is not obvious to him. The substance of Hall's (1980) exposition is that existing accounts of culture are trapped in a binary opposition between the Scylla of an overemphasis on 'conditions' and the Charybdis of a too-inclusive emphasis on 'consciousness'. The former, the preoccupation with conditions, dominates the thinking of what Hall (1980) dubs 'structuralism'; 'culturalism' on the other hand is fixated on the role of consciousness. In brief, culturalist accounts, in Hall's interpretation, pivot on the primary role of experiences and subjects in explaining the character of cultural formations; in contrast, for structuralists, experience is but a derivative product and an 'effect' of contextual categories, classifications and frameworks structuring society at large. Hall (1980) is at pains to stress that both positions have their drawbacks. The preoccupation with the social, political and economic circumstances characteristic of structuralism can dissolve human agency; on the other hand, the attempt to anchor analysis in the subjective experiences carries the danger of succumbing to what Hall dubbed "naïve humanism" (1980, p. 67), which risks losing sight of the fact that people are born into determinate conditions. Thus, both positions have their limitations. Yet each also carries a grain of truth, and for this reason, Hall (1980) is vehement that both positions are necessary for the purposes of anchoring cultural analysis: neither structuralism nor culturalism will do "as self-sufficient paradigms of study" (1980, p. 72). Indeed, to get ahead, we need to look at the relationship between the two. Practice theories present a promising way forward.

As outlined in Ortner's (1984) seminal text, practice theory "seeks to explain the relationship(s) that obtain between human action, on the one hand, and some global entity which we call 'the system' on the other" (p. 148). In other words, the approach seeks to resolve the antinomy between the 'objectivism' of structuralism, while at the same time not giving in to the 'subjectivism' of culturalist 
approaches and to explain how agency and contexts interact (Ortner, 1984, pp. 144 ff.). To this end-and in line with pragmatist assumptions - practice is made the primary object of analysis. This is what unites the big names of the first-generation practice theorists: Bourdieu (1977); Giddens (1984) and Ortner (1984), with the second generation represented by Andreas Reckwitz (2002), Theodore Schatzki (2002) and Elizabeth Shove (Shove, Pantzar, \& Watson, 2012), to name just a few. What differentiates the post-classical, second generation is their cautious attitude toward abstract generalisations and their interest in developing in-situ studies. That this should be the case comes across in the description of practice offered by Reckwitz (2002, p. 249):

A 'practice'. . . is a routinized type of behaviour which consists of several elements interconnected to one another: forms of bodily activities, forms of mental activities, 'things' and their use, a background knowledge in the form of understanding, know-how, states of emotion and motivational knowledge.

Following on from their understanding of what is at issue in practices, the contemporary practice theory approaches force some interesting shifts in terms of how the analysis is framed and what methodologies are useful. They move the analysis to the meso level where the traditional microlevel ideas about human agency and the macro-level accounts of material conditions are revised and recombined in a way that eschews the traditional notion of 'mediation'. ${ }^{8}$ This does not mean that practice theories dissolve human agency by adopting mechanistic and deterministic conceptions of subjective action. Rather, they are interested in developing methodological approaches with flat, or perhaps flatter, ontologies where minds, bodies, objects, structures and discourses come networked and interconnected (see Latour, 2005). Indeed, while refusing to give up the notion of agency, Reckwitz (2002) was able to acknowledge the centrality of 'things and their use' by arguing that a practice "necessarily depends on the existence and specific interconnectedness of these elements, and which cannot be reduced to any one of these single elements" (p. 250). Reckwitz, Schatzki and others made it clear that the reproduction of practices in everyday life can only be understood in a networked fashion and, to this end, the flatlining of material practices and symbolic constructions into one networked constellation is required.

These theoretical and methodological developments have been applied-with a varying degree of success - to studying practices in the world, most notably in media research (Couldry, 2004) and the sociology of consumption (Warde, 2005; 2014). As we will see in the next section, they have also been applied directly to cultural value. It is this body of work that makes apparent the huge potential but also the limitations of theories of practice. 


\section{Cultural Value and the Practice Turn?}

What would it mean to introduce practice theories in the exploration of cultural value and how might this be done? There are some instructive precedents. In fact, one of the founding fathers of practice theory-Bourdieu $(1977 ; 1990)$ - proposed that cultural value should be analysed as a form of intersubjective interaction, part of the complex socio-cultural system. It may also be pointed out that Bourdieu's positioning of cultural value within the frame of interactions, shared habitus, field positions and social structures is not dissimilar - at least insofar as the focus in concerned-to those anthropological accounts which look at culture value in relation to that "complex whole which includes knowledge, belief, art, morals, law, custom and any other capabilities and abilities acquired by a man as a member of society" (Tylor, 1958, p. 1)-most prominently Raymond Williams with his culture as a 'way of life' account (Williams, 1983). Thus, in both Bourdieu and Williams, we could look for early attempts to think about cultural value through a lens of practice, however not without problems (and indeed, in the case of Williams, not without some stated opposition ${ }^{9}$ ).

While Bourdieu's approach to cultural value may seem like an attempt to develop a fully fledged theory of practice, it remains stranded with a host of problems of the structuralist approach because of the weight it gives to the notions of habitus; the overdetermination of social action precluding effectively meaningful agency being the most prominent problem (see King, 2000). In other words, what we have in Bourdieu is admittedly an account of value that is socially situated and determined and yet, one that remains mechanistic and static. Arguably, neither does Raymond Williams (1961) offer a satisfactory answer. Not only does Williams's account suffer from overemphasising structuralism (Jones, 2004) but in addition, it is driven by the imperative to expand-rather than abolish-the aesthetic concept of culture (Bennett, 1992; 1993). Thus, both Bourdieu and Williams fail to capitalise on the potential opened up by practice theory. Bourdieu, in spite of his best intentions, remains wedded to structural analysis which pre-empts any detailed understanding of how cultural valuation takes place in specific contexts for specific individuals. ${ }^{10}$ With the similar outcome but for different reasons, Williams's thinking about cultural value remains blind to the stratification of cultural consumption and returns us back to the universal aesthetic and ethical forms of the 'general human culture'. In this sense, both Bourdieu and Williams are unable to respond to the challenge discussed by DiMaggio (1997) and set by Swindler (1986), when she calls for a new model of cultural influence-one sensitive to social stratification and with a more differentiated understanding of causality-where cultural value could be reconstructed in terms of "resources from which people can construct diverse lines of action" rather than the ultimate normative source shaping action uniformly across all individuals (see Swindler, 1996, p. 273). 
What would it mean to re-conceive cultural value through the lens of practice theories while remaining sensitive to the discussions in cultural sociology and cognitive sciences? It could mean studying cultural value as a subject in the relatively new area of inquiry called valuation studies, in particular, as part of the growing stream of research on the social practice of valuation and sociocultural valuing conventions (Aspers \& Beckert, 2011; Callon \& Muniesa, 2005; Karpik, 2010; Kornberger, Justesen, Madsen, \& Mouritsen, 2015; Lamont, 2012). Significantly, radical and important proposals for studying valuation made in the tradition of pragmatic sociology, notably by Boltanski and Thévenot (2006), are in need of empirical testing and it might be that explorations into cultural value provide a fertile ground for this. What renders valuation studies attractive is the key assumption that value is a quality that is constructed and/or contested and that it requires effort and energy to establish and maintain (see for instance, Antal, Hutter \& Stark, 2015). Revisiting some ideas of Cooley (1912), Dewey (1913; 1939) and other pioneers of the old pragmatic tradition (see Muniesa, 2012) and taking inspiration from work on value in anthropology (Appadurai, 1986; Eiss \& Pedersen, 2002; Graeber, 2001; Thompson, 1979), valuation studies reject the static accounts of value where value is either thought of as a property of an object or as something inherent in the subjective judgement of individuals. Rather, valuation is to be approached as a judgment of practice, a kind of social action and a matter of empirical inquiry.

The outcome of applying practice theories is to reconfigure cultural value as processual and relational in situ. This approach-badly needed as it is-will however not provide an exhaustive answer to understanding cultural value in the absence of accounts dealing with experiences on the one hand and those analysing macro structures in politics and economy. This is down to the limitation of practice theories. As apparent from the discussion between by Schatzki and Friedland (Friedland, 2018), while practices might be recognised to form basic reality, practices cannot be the only reality as there are many aspects of human life that cannot be treated adequately at the level of practice: experiences and institutions being two pertinent ones in the current discussion. And thus, whilst recognising the need to be vigilant of the dangers of psychologism, methodological individualism and those tendencies in cultural studies that reduce the cultural to meanings in the head (as discussed above), it is obvious that the range of experience-centred approaches championed in the AHRC Cultural Value Project are here to stay. At the other end of the spectrum, practice theories are also in need of being supplemented by general theories of political economy and approaches capable of "illuminating the institutional or systemic conditions of existence of those practices" (Warde, 2014, p. 298). In this context, whilst perhaps resisting the kinds of structuralism practiced by Bourdieu and Williams, the type of structuralist insight offered for 
instance in Friedland and Alford's accounts of institutional logics (Friedland \& Alford, 1991) certainly deserves a second look in relation to cultural value.

\section{Where Now for Cultural Value?}

In spite of the limitations outlined above, the suggestion is to embrace the practice turn in order to explore what this framing can offer. This does not mean dismissing all the other explanatory frames and methodological frameworks. If we admit, as we should, that analysing experiences and social structures is essential if we want to develop a comprehensive framework for understanding cultural value, our next step has to be to test the compatibility of the threesome arrangement spanning practice theories, institutional analysis and forms of inquiry such as phenomenology informed by the new insights from cognitive science. Introducing the practice theory perspective will mean that new methodologies will have to be developed specifically in relation to cultural value. As a general headline, non-representational and assemblage thinking (Thrift, 2007) and actor-network approaches (Latour, 2005) are likely to have something to offer by directing attention to the role of 'non-human' agents. These however will have to be 'operationalised' in terms of concrete methods. Likewise, the theories developed by the French pragmatists and convention theorists (Boltanski \& Thévenot, 2006; Storper \& Salais, 1997) can and should be tested through methods developed by valuation studies, e.g. an observational network approach to valuation (Stark, 2013). Looking explicitly at the developments in relation to cultural value, the potential of some proposals to be used in conjunction with practice theory should be assessed; notably, the possibility of integrating the configurational (Oancea, Florez-Petour, \& Atkinson, 2015) and ecological (Dovey, Moreton, Sparke, \& Sharpe, 2016) models, as well as integrated reporting (Meyrick, 2016), deserve more attention. From the point of view of the author of this article, spatialising and temporalising of cultural value using concepts developed in design scholarship (Bjögvinsson, Ehn, \& Hillgren, 2012; Binder, Ehn, De Michelis, \& Jacucci, 2011) appears an attractive proposition. Thus, developing the practice theory approach is not free of challenges; the pay offs however may well be worth the effort. In particular, the three following likely outcomes are worth considering.

\section{Overcoming the separation of conditions and consciousness}

The proposal made here is that framing cultural value as a form of practice could destabilise the opposition outlined by Hall (1980, see above). The advantage of the proposed approach is that it resists reducing cultural value to psychologism or culturalism, and instead it looks at the entire 'culture complex' (Bennett, 2015) as firmly embedded in the material. Nor does the proposed approach explain away cultural value by dissolving it into social patterns and material conditions. 
Rather, it views cultural value as constituted through the interweaving of the collective agency, structures and material conditions. In other words, the practice theory approach presents a way of moving away from the idealist and psychologistic conceptions of culture equating it with symbolic representations and meanings ${ }^{11}$ in the head on the one hand, and away from reducing culture to social structures on the other.

\section{Getting over the mediation between the bodily and the cognitive}

The proposed approach not only problematises the relationship between the symbolic and the material orders, it also unsettles the assumed relationship between the bodily and the cognitive. Practice theories enable us to move away from the purely cognitive models of action and representation and to consider the role of embodiment, equipment and other material constraints. The practice theory lens offers an alternative and an antidote to the entrenched mind-body dualism in that it recognises that "experience is produced not by disembodied rational agents but socially mediated and embodied people, guided as much by reasons as by affects and emotions, whose actions are tempered by the physical arrangements that embed bodily activity in this context" (Schatzki, 2002, p. 80). By accepting that human agency is embodied and environmentally embedded, the approach proposed here departs from the model of rational agency underpinning methodological individualism.

\section{Getting unstuck between the 'best and brightest' and the 'everyday'?}

Perhaps the most welcome implication of embracing the practice theory approach is the potential for dissolving the counterproductive tension between two allegedly competing definitions of culture: the 'aesthetic' and the 'everyday'. The former can be traced to the Arnoldian/Leavisite tradition of 'best and brightest' (Arnold, 1993; Leavis, 1950) and is often caricatured as reducing the value of culture to the connoisseurship of a rarefied set of privileged cultural objects; the latter, sometimes referred to as the anthropological account, considers culture as a 'way of life' and dates back to Tylor (1958) through Williams (1983). It should be noted that the dyad of the 'aesthetic' and the 'everyday'-rather than signifying some qualitative and substantive difference-reflects a host of questions concerning social differences, access to culture and cultural policy practice. Indeed the 'definition' of culture offered by Geertz (1973) - where culture is defined as the publicly available symbolic forms through which people experience and express themselves ${ }^{12}$-makes this point rather well. This said, this polarisation-more recently echoed in the 'false' distinction between democratising culture and cultural democracy (see Evrard, 1997)-has crippled the discussions of cultural value (see for instance Gross \& Wilson, 2018). The approach proposed in this chapter 
promises a way out of this impasse. Rethinking cultural value as a form of practice has the consequence of approaching culture as both: normative arrangements structuring attitudes, influencing choices and orienting actions, and also a product of these arrangements in various guises, including the canonical, aesthetic forms of culture but also the everyday forms of participation. A less technical way of putting this point would be that Williams's (1983) culture as a way of living and orienting action provides the 'soup' in which Arnold's (1993) floats. If 'culture' is both - the medium and the outcome-cultural value, analysed from the view point of practice theory, bridges both.

To conclude, the proposal of this chapter is to devote more time and energy to researching cultural value at the meso level and as a form of practice. This line of research does not require that we abandon other approaches, be it on the micro (individual) or the macro (structural) level. In this sense, it should be obvious that the proposed approach springs from and builds on the AHRC Cultural Value Project and the Cultural Value Scoping Project. It however goes further in suggesting new directions. The main point is that, as Shove (2017) once remarked, "taking 'practice' as a central conceptual unit of enquiry generates a range of distinctive questions" ${ }^{13}$. It is the possibility of asking these new questions that makes this future direction attractive.

\section{References}

Antal, A. B., Hutter, M., \& Stark, D. (Eds.). (2015). Moments of valuation: Exploring sites of dissonance. Oxford: Oxford University Press.

Appadurai, A. (Ed.) (1986). The social life of things: Commodities in cultural perspective. Cambridge: Cambridge University Press.

Archer, M. S. (1982). Morphogenesis versus structuration: On combining structure and action. British Journal of Sociology, 33(4), 455-483

Arnold, M. (1993). 'Culture and anarchy' and other writings. Cambridge: Cambridge University Press.

Aspers P., \& Beckert, J. (Eds.). (2011). The worth of goods: valuation and pricing in the economy. New York: Oxford University Press.

Belfiore, E. (2002). Art as a means of alleviating social exclusion: Does it really work? A critique of instrumental cultural policies and social impact studies in the UK. International Journal of Cultural Policy, 8(1), 91-106.

Bennett, T. (1992). Useful culture. Cultural Studies, 6(3), 395-408.

Bennett, T. (1993). Being 'in the true' of cultural studies. Southern Review, 26(2), 217-238.

Bennett, T. (2015). Cultural Studies and the Culture Concept. Cultural Studies, 29(4), 546-568. 
Berger, P., \& Luckmann, T. (1991). The social construction of reality, a treatise in the sociology of knowledge. London: Penguin Books.

Binder, T., Ehn, P., De Michelis, G., \& Jacucci, G. (2011). Design things (design thinking, design theory). Cambridge, MA: MIT Press.

Bjögvinsson, E., Ehn, P., \& Hillgren, P-A. (2012). Design things and design thinking: Contemporary participatory design challenges. Design Issues, 28(3), 101-116.

Boltanski, L., \& Thévenot, L. (1999). The sociology of critical capacity. European Journal of Social Theory, 2(3), 359-77.

Boltanski, L., \& Thévenot, L. (2006). On justification, economies of worth. Princeton: Princeton University Press.

Bourdieu, P. (1977). Outline of a theory of practice. Cambridge: Cambridge University Press.

Bourdieu, P. (1990). The logic of practice. Cambridge: Polity.

Callon, M., \& Muniesa, F. (2005). Peripheral vision: Economic markets as calculative devices. Organization Studies, 26(8), 1229-1250.

Cooley, C. H. (1912). Valuation as a social process. Psychological Bulletin, 9(12), 441-50.

Couldry, N. (2004). Theorising media as practice. Social Semiotics, 14(2), 115-132.

Crossick, G., \& Kaszynska, P. (2016). Understanding the value of arts and culture (AHRC Cultural Value Project report). Swindon: AHRC.

Dewey, J. (1913). The problem of values. Journal of Philosophy, Psychology and Scientific Methods, 10(10), 268-269.

Dewey, J. (1939). Theory of valuation. Chicago: University of Chicago Press.

DiMaggio, P. (1997). Culture and cognition. Annual Review of Sociology, 23, 263-287.

Dovey, J., Moreton, S., Sparke, S., \& Sharpe, B. (2016). The practice of cultural ecology: Network connectivity in the creative economy. Cultural Trends, 25, 87-103.

Eiss, P., \& Pedersen, D. (2002). Introduction: Values of value. Cultural Anthropology 17 (3), 283-290.

Evrard, Y. (1997). Democratizing culture or cultural democracy?. Journal of Arts Management, Law, and Society, 27(3), 167-175.

Farrell, B. (2016). Understanding the value of arts and culture: The AHRC Cultural Value project by Geoffrey Crossick and Patrycja Kaszynska. Cultural Trends, 25(4), 273-276.

Friedland, R. (2018). What good is practice?: Ontologies, teleologies and the problem of institution. M@n@gement,4(21), 1357-1404.

Friedland, R., \& Alford, R. R. (1991). Bringing society back in: Symbols, practices, and institutional contradictions. In W. W. Powell \& P. J. DiMaggio (Eds.), The new institutionalism in organizational analysis (pp. 232-263). Chicago: University of Chicago Press.

Geertz, C. (1973). The interpretation of cultures. New York: Basic Books.

Giddens, A. (1984). The constitution of society: Outline of structuration theory. Cambridge: Polity Press.

Graeber, D. (2001). Toward an anthropological theory of value: The false coin of our own dreams. New York: Palgrave.

Gross, J., \& Wilson, N. (2018). Cultural democracy: An ecological and capabilities approach. International Journal of Cultural Policy, doi: 10.1080/10286632.2018.1538363 
Hall, S. (1980). Cultural studies: two paradigms. Media, culture and society, 2, 57-72.

Heath, J., Methodological individualism. In E. N. Zalta (Ed.), Stanford Encyclopedia of Philosophy (Spring 2015 ed.), Retrieved from https://plato.stanford.edu/archives/spr2015/entries/methodological-individualism/

Jones, P. (2004). Raymond Williams's sociology of culture. A critical reconstruction. London: Palgrave Macmillan UK.

Kahneman, D. (2011). Thinking, fast and slow. London: Allen Lane.

Karpik, L. (2010). Valuing the unique: The economics of singularities. Princeton: Princeton University Press.

Kaszynska, P. (2017). The Cultural Value Scoping Project. London: AHRC, PHF and KCL.

Kaszynska, P. (2020). Cultural value and economic value in the arts and culture. In A. Mignosa, R. Towse, \& T. Bille (Eds.), Teaching cultural economics. London: Edward Elgar Publishing.

King, A. (2000). Thinking with Bourdieu against Bourdieu: A 'practical' critique of the habitus, Sociological Theory, 18(3), 417-433.

Kornberger, M., Justesen, L., Madsen, A. K., \& Mouritsen, J. (Eds.) (2015). Making things valuable. Oxford: Oxford University Press.

Lamont, M. (2012). Toward a Comparative Sociology of Valuation and Evaluation, Annual Review of Sociology 38(21), 201-221.

Latour, B. (2005). Reassembling the social: An introduction to actor-network theory. Oxford: Oxford University Press.

Leavis, F. R. (1950). The great tradition. New York: George W. Stewart, Publisher Inc.

Meyrick, J. (2016). Telling the story of culture's value: Ideal-type analysis and integrated reporting. Journal of Arts Management, Law, and Society, 46 (4), 141-152.

Miles, A., \& Gibson, L. (2016). Everyday participation and cultural value. Cultural Trends, 25(3), 151-157.

Muniesa, F. (2012). A flank movement in the understanding of valuation. Special Issue: Sociological Review Monograph Series: Measure and Value edited by L. Adkins \& C. Lury, 59(2), 24-38.

Oancea, A., Florez-Petour, T., \& Atkinson, J. (2015). The ecologies and economy of cultural value from research. International Journal of Cultural Policy, 1-24, doi: 10.1080/10286632.2015.1128418

Ortner, S. B. (1984). Theory and anthropology since the sixties. Comparative Studies in Society and History, 26(1), 126-166.

Reckwitz, A. (2002). Toward a theory of social practices. A development in culturalist theorizing. European Journal of Social Theory, 5, 243-263.

Rushton, M. (1999). Methodological individualism and cultural economics. Journal of Cultural Economics, 23, 137-147.

Schatzki, T. (2002). The site of the social: A philosophical account of the constitution of social life and change. University Park, PA: Pennsylvania State University Press.

Shove, E. (2017). Practice theory methodologies do not exist. Practice theory methodologies. Retrieved from https://practicetheorymethodologies.wordpress.com/2017/02/15/elizabethshove-practice-theory-methodologies-do-not-exist/ 
Shove, E., Pantzar, M., \& Watson, M. (2012). The dynamics of social practice: Everyday life and how it changes. London: Sage.

Stark, D. (2013). Observing finance as a network of observations. Sociologica, 2, 1-12.

Stern, M. J., \& Seifert, S. C. (2016). Understanding the value of arts and culture: The AHRC Cultural Value Project by Geoffrey Crossick and Patrycja Kaszynska. Cultural Trends, 25(4), 277-279.

Storper, M., \& Salais, R. (1997). Worlds of production. The action frameworks of the economy. Harvard University Press, Cambridge, MA.

Swindler, A. (1986) Culture in action: Symbols and strategies. American Sociological Review, 51, 273-286.

Thompson, M. (1979). Rubbish theory. Oxford: Oxford University Press.

Thrift, N. (2007). Non-representational theory: Space, politics, affect. London: Routledge.

Tylor, E. (1958). Primitive culture. New York: Harper \& Row.

Warde, A. (2005). Consumption and theories of practice. Journal of Consumer Culture, 5(2), 131-153.

Warde, A. (2014). After taste: Culture, consumption and theories of practice. Journal of Consumer Culture, 14(3), 279-303.

Warwick Commission. (2015). Enriching Britain: Culture, creativity and growth: The 2015 report by the Warwick Commission on the Future of Public Value. Coventry: University of Warwick. Retrieved from https://warwick.ac.uk/research/warwickcommission/futureculture/finalreport/warwick_com mission_report_2015.pdf

Weber, M. (1922[1968]). Economy and society. Berkeley: University of California Press.

Williams, R. (1961). The analysis of culture. In J. Storey (Ed.), Cultural theory and popular culture: $A$ reader. London: Pearson.

Williams, R. (1983). Keywords: A vocabulary of culture and society. Oxford: Oxford University Press.

\footnotetext{
${ }^{1}$ Retrospectively, it has become apparent to the author that-even though it was not articulated in those terms at the time in Crossick and Kaszynska (2016) - the argument here concerns the plurality of valuing conventions in the new pragmatist French sociology. See for instance 'orders of worth' (Boltanski \& Thévenot, 2006) or 'action frameworks' (Storper \& Salais, 1997).

${ }^{2}$ What has become apparent to the author after the Cultural Value Project report had been published is that it is useful to distinguish between the primacy of individual experience in ontological and epistemological senses. While the first simply states that the arts and culture have to be experienced by someone for there to be any effect; the latter might be taken to imply explanatory priority: that the effects of engagement have to be explained in terms of individual experiences before other social and economic registers can be introduced. The latter position can be seen as problematic (see the discussion of methodological individualism).

${ }^{3}$ This repositioning of individual experience to the centre of inquiry was coupled with a further attempt to realign the discourse through deconstructing some prevalent-yet arguably misguided-conceptual dichotomies such as: intrinsic $v$ instrumental, high $v$ popular, the amateur $v$ the professional, the publicly funded $v$ the commercially oriented, and audience $v$ participants.

${ }^{4}$ It is important to stress however that the postulated primacy was never intended as a rejection of the more 'holistic' approaches, such as those derived from statistics or ecosystem analysis, to name just two. Rather, it was a matter of rebalancing and complementing.
} 
${ }^{5}$ Culture in DiMaggio's article is used in the anthropological sense to mean the system of meanings, practices and arrangements rather than the domain associated with the arts, heritage and museums in the narrower use of the term 'culture'. This is not an issue from the point of view of the present chapter because culture in the narrow sense is taken to be a manifestation of the wider understanding of culture.

6 "The dominant template of consumption in all disciplines remains modelling the individual engaged in many discrete acts wherein personal deliberation precedes personal, independent decisions made with a view to the satisfaction of preferences. The ever greater prominence of neo-liberal political and economic doctrine has given further impetus to this tendency to postulate the autonomy of the individual and freedom of individual choice" (Warde, 2014, 283).

${ }^{7}$ The report went as far as to suggest that these interactions be approached in terms of 'wicked problems'the situation where the views of policy makers, cultural sector practitioners and academics meet and indeed, clash and where the ultimate conflict resolution may not be possible (Kaszynska, 2017, p. 24).

${ }^{8}$ In fact, they could be said to attack the model of the sovereign subject in that-in the words of Warde-they

"emphasise routine over actions, flow and sequence over discrete acts, dispositions over decisions, and practical consciousness over deliberation" [moreover, as Warde continues] "In reaction to the cultural turn, emphasis is placed upon doing over thinking, the material over the symbolic, and embodied practical competence over expressive virtuosity in the fashioned presentation of self" (Warde, 2014, p. 286).

${ }^{9}$ Raymond Williams, as a self-proclaimed Marxist, was critical of practice theories because they were allegedly unable to deal with the questions of power (see Jones, 2004).

${ }^{10}$ Boltanski and Thévenot do in fact explain the raise of pragmatic sociology as a reaction to Bourdieu's inability to recognise that human agency is not entirely predetermined by the social (Boltanski \& Thévenot, 1999).

${ }^{11}$ Insofar as the proposal is to reconceive through networked approaches what has been traditionally thought as a binary relation, it might be suggested that what is on offer is a new way of studying structuration: one where the relationship between agency and structure is not dialectical but distributed (cf. Berger \& Luckmann, 1991; Archer, 1982; Giddens, 1984).

${ }^{12}$ Geertz defines culture as "a system of inherited conceptions expressed in symbolic forms by means of which men communicate, perpetuate, and develop their knowledge about and attitudes toward life" $(1973,89)$.

${ }^{13}$ https://practicetheorymethodologies.wordpress.com/2017/02/15/elizabeth-shove-practice-theorymethodologies-do-not-exist/ 